\title{
O CONCEITO DE VARIACÃO LINGÜÍSTICA NAS TEORIAS DA LINGUAGEM NA INDIA ANTIGA
}

Carlos Alberto da Fonseca

Universidade de São Paulo

Resumo: 0 autor alinhava, com alguns exemplos extraídos da fonologia, da fonética, da semántica, da morfologia e da sintaxe sánscritas, alguns argumentos para a corroboração da idéia de que toda a teoria lingüística desenvolvida na India antiga estava baseada na constatação da variaçåo lingübtica experimentada na vida cotidiana $e$ representada ao longo do tempo nas mais variadas formas assumidas pela língua indiana.

Palavras-chave: Sânscrito, Variação lingüística, Lingüística indiana.

Quando se consegue furar a sólida barreira, construída com os tijolos da reflexão descuidada e o cimento da metodologia ultrapassada, por parte tanto dos sanscritistas quanto dos historiadores da linguagem ou da lingüistica, e, então, aquilo com que se depara é os textos originais em seus contextos originais, uma paisagem se descerra diante de nossos olhos mentais, feita de formas mais bem delineadas, batidas por luzes mais claras, arejada pelos ventos do respeito ao ser humano. Passados já dois séculos, pelo menos, de viagens apetrechadas pelo saber indiano antigo sobre a linguagem, percebe-se que esses roteiros bisseculares não mapeiam a superfície, que os repastos prometido são indigestos, que os guias não estão imbuídos do prazer da descoberta, que na bagagem não há roupas nem calçados adequados. Em suma, que é preciso planejar tudo de novo - mas ouvindo as vozes que murmuran coisas com sentido por entre as linhas, nas entrelinhas de estradas que vêm do fundo dos tempos para nos pegar de calças curtas diante da sabedoria, da eficiência, do humanitismo e da modernidade de reflexões que os tempos e os viéses da espiral da História sepultaram entre as pedras do preconceito e os musgos da vontade de poder.

É bem assim, nos momentos escuros da intermitência desse lucro-fusco, entre muitos equívocos e erros repetidos à exaustão e alguns acertos sobre os quais não se medita,é al que està, por exemplo, mal situada a questão da variação lingüística na India antiga, cuja consciência baseou, permeou e norteou toda a investigação sobre a linguagem ali levada a efeito. Nunca, na India antiga, sondada ela com uma compreensão mais acurada, nunca ali uma consideração da variante como exceção, nunca uma questão de "certo e errado", 0 ato de fala bem realizado culminando na obtenção do "mérito (religioso)", da "prosperidade", da "felicidade suprema". Do outro lado, do lado dos viajantes, sempre o sagrado, o religioso, 0 prescritivo, o perfeito, o único, o certo, o errado, o decadente, o confuso, os deuses ditando textos , Panini inventando uma língua, a confusão entre letra e fonema, entre 
a escrita e a oralidade, um povo que troca de língua sem mais e nem menos - tudo isso num outro "dicionário de idéias feitas / recebidas" de fazer inveja a Flaubert...

$\mathrm{Na}$ verificação mais detida da organização e dos objetivos das obras que compõem a investigação lingülstica indiana antiga, na compreensão mais cuidadosa do sentido lingüístico da terminologia e do material nelas examinado, depreende-se com extrema clareza o fato de que na India antiga foi privilegiada - tanto na organização social das varna e das jäti quanto na pluriforme devoção/bhakti religiosa e na configuração dos deuses/mitos, mas também no que diz respeito à questão da linguagem - a consideração da diferença e, em conseqüência, a vinculação dos estudos lingüisticos à conciência de que as pessoas utilizam 0 código lingüístico comum de modos distintos, cada um deles organizado/recortado consensualmente em determinado tempo, em determinado espaço, em determinadas circunstâncias. Como se pode verificar, na Astädhyāyi de Pánini, no Nirukta de Yāska, nos prätiçäkhya e em comentários e teơrizaçōes posteriores, 0 que está em causa, ao lado da "descrição analítica" (este é o significado do termo vyäkarana, que nos acostumamos a entender como "gramática [normativa]") de uma norma de uso, e além da consideração de outras normas de uso, é um cuidado todo especial, que não passa pelo "normativo" (no sentido de "ditar regras/normas"), para um dimensionamento das possibilidade múltiplas do falar.

Assim é que, para começar este convite, é preciso lembrar que todos os termos que, em línguas ocidentais, remetem ao conceito de "linguagem" correspondem, em sânscrito, apropriadamente (bhäsä, ukti, bhäsana, bhäsita, vacana, vacas, väkya, vyähära, väni, nigada, nigàda, väc, lapită, abhilàpa, vadanti), a fala, a de fala, ao ato de comunicação, de troca de informaçōes e conteúdos pela via de realização plena da natureza humana pela palavra partilhada. Como afirma a Kenopanișad, "a fala é a essência do homem" (purușasya vāgrasah/ ), expressão que ecoa a definição que Pānini formulou, na concisão de sua visada antropocêntrica, do que seja o homem, o falante: vyakatavàc "aquele que tem a fala articulada / diferenciada" ou aquele que é diferente pela fala - visão que atribui aos dois falantes participantes mínimos obrigatórios de uma conversa a radicalidade da diferenciação máxima possivel entre seus modos de falar. E Pänini, no século $\mathrm{V}$ a. C., está apenas formalizando cientificamente, tecnicamente, umà imagem poética védica que falava da diferença de linguagens entre homens distintos socialmente que se expressavam por meio de uma "trama de farrapos" ou que se entregavam a uma "mulher sedutora ricamente enfeitada". Como brocadostambém se convertem em farrapos e as joias de uma mulher podem ser falsas, os dois limites estabelecidos pelo poeta védico são uma ilusão, são movediços,expansiveis, recaracterizáveis.

Primeiro conceito a que se deve prestar atenção: praknti "base, fundamento, matéria-prima. Alojada na buddhi "consciência" ou na citta "mente" ( = "pensamento", "pensado", cf. thought, pensée), constitui uma "massa amorfa" (arüpa), um "armazém" (älaya), composta de e ocupada por "marcas" (väsanä), "construções" mentais (samskära) ou "formas especificas" (äkrti), provenientes da apropriação/abstração da realidade pelos órgãos dos sentidos e pelo manas "pensamento" e por este categorizado como resistências / re-existências na condição de "notificações / referências" (vijñäptimätra) do / ao mundo real. Algo puramente mental, uma propriedade coletiva, "absoluta" (brahman) no sentido de "totalizante / globalizante / unificante"; algo virtual, tecido de conceitos e de relações 
entre conceitos, marcado pelas coordenadas ideológicas que regem a cultura. Garantia de pertinência a essa cultura.

A partir dal, apenas diferenças: apenas diferentes organizações fenomênicas dependentes da maior ou menor identificação dos falantes a um ätman , a uma "individualização", a um "si". De um lado, os präkrta, formalizados diretamente a partir da "base", os prácritos, os vernáculos, distribuídos regionalmente, tal como são primordialmente diferenciados regionalmente os falantes, que sofreram e fizeram pequenas histórias diferentes dentro da grande história da cultura. De outro lado, uma forma "modificada" (vaikrta), cultivada, concebida como "rebuscada / temperada / cozida", samskrta, sânscrito, utilizada por alguns grupos sociais dominantes, detentores do saber e do poder, uma forma considerada de prestígio.

Cabe ressaltar, entretanto, que os objetos lingülsticos assim recobertos por esses adjetivos saminkrta e präkrta são, na verdade, dois grandes feixes de registros bastante bem identificados: mais conservador um. o Sânscrito, norma culta, que manteve em toda parte do subcontinente por onde se disseminou e ao longo de todos os tempos uma suposta homogeneidade ragantida pela fixação lingüística operada mais pela literatura do que pela "gramática"; muito menos conservador 0 outro, os Prácritos, formas do indiano vulgar, já diferenciados entre si de uma região para outra e que sempre se deixaram marcar pela mudança lingülstica, a despeito de suas "gramáticas".

Vale, ainda, afinar uma pouco mais essas diferanças. Já no período védico, durante o processo de elaboração das bases da cultura indiana, em meio ao complexo jogo definitivação de valores àrya/ invasores e drāvida/ autóctones no vale do Indo, naqueles séculos recuados, já se referiam os poetas a essa divisão com suas metáforas alusivas a uma "mulher enfeitada" (o Sânscrito) e a uma "trama de farrapos" (o Prácrito). 0 que não referem, mas é perceptivel, é uma diferença nos Sanscritos: como se sabe, esses poetas viveram em regiōes diferentes do vale do Indo, sujeitas a influências lingüisticas diferentes - de modo que, nos seus poemas, de uma familia de poetas para outra, de poemas mais antigos para poemas mais recentes, é possivel perceber que algumas mulheres são mais enfeitadas que outras ou usam enfeites que outras rejeitam; de modo que se pode perceber a predominância de temperos na cozinha lingülstica de poetas / famílias / épocas diferentes. Além disso, ao longo da hisória, foram várias as formalizações por que passou a língua indiana na sua formação culta: que diferenças existem entre 0 Sânscrito Védico e o Sånscrito Clássico! Por outro lado, conhecidos desde o período védico, os Prácritos vão se materializar nos editos em pedra e pilares de Açoka, terão sua primeira análise no "Tratado de Bharata sobre o Teatro" (já que o chamado Teatro Sânscrito inclui falas em Prácritos, os atores tinham de conhecê-los), sofrerão influências dos conquistadores estrangeiros e resultarão nos falares modernos. Nada de novo sob o sol.

Uma outra volta no parafuso. Do mesmo modo que a fala dos poetas de uma família védica não é essencialmente a mesma dos poetas de outra família, assim também Kälidäsa não é Bhavabhüti, o Mahäbhärata não é o Rämāyana, etc. Referir Kälidäsa e Bhavabhüti, escritores, pode sugerir discussões sobre "estilística" e não "lingüistica". Mas é que nosso sentido do lingülstico, apesar das teorias abrangentes e avançadas, anda meio curto na prática e na reteorização: se o estilo, para nós, por exemplo, já foi um clássico "não sei quê" e um desvio em nossa luta 
nas linhas e entrelinhas pelo vigor de uma norma ou da Língua, para os indianos antigos, que sempre recusaram o mais que puderam a escrita (os grammata), 0 estilo, a projeção/marca do indivíduo/falante, era apenas um dos muitos "caminhos / encaminhamentos" (märga, riti) possíveis dentro do sistema, utilizados na dependência única e absoluta da homologação entre forma e conteúdo do que se devia / queria dizer. E nem por isso a lingua se degenerou. Nem por isso a unidade lingüistica se rompeu.

Sensação de desconforto. Diante dessa pletora de formas/normas, reconhecimento radical da liberdade lingüistica vigiada, como resistir à tentação de rebaixar o tônus dessa lingüistica indiana que, esgueirando-se por entre o diferente, e porque o levava em estrita consideração, foi capaz de pensar mais generosamente 0 ato de fala em todas as suas formas e tudo o que ele implica ou esta nele implicado? Escrita em Sânscrito - não havia outro modo, este era o registro do saber -, essa lingüística não pensa apenas a norma culta, ou elabora uma teoria geral da linguagem que tem como objeto apenas o Sânscrito: existe toda uma tradição de "gramáticas" prácritas e de estéticas em Prácritos... E, mesmo quando fala apenas do que chamamos Sâncrito no singular, esta atenta para a pluralidade dessa forma em muitas normas de igual prestígio. Como dirá Patañjali, pensando em termos morfológicos uma estrada é o "significado" (sphoṭa) a ser transmitido: não importa que por ela passem um homem a pé, a cavalo ou sobre um elefante, que homem e montaria a percorram devagar, depressa ou em velocidade, que caiamm nos buracos ou se desviem deles, que se sujem ou não de pó: essas possibilidades são os "significantes" (dhvani), realizações fônicas induviduais, alofones. Como, mais tarde, dirá Bhartrhari, pensando agora em termos de frase, a estrada, no fundo, é que é diferente: 0 "significado" será outro conforme o conceito que o sujeito tiver da estrada. Como dirá, entre os dois, Çäkațāyana, o importante é que, na comunicação do dia-a-dia, 0 artha "referente" seja entendido pelo destinatário.

Vejam-se, a título de exemplo, algumas descrições de variação lingüística. Para começar, algumas possibilidades de solução do encontro de /e/ e /0/ finais de uma palavra com uma vogal na palavra seguinte. As formulaçōes provêm das análises fonéticas do prätiçäkhya (= manual de fonética e fonologia) da escola exegética Taittiriya ${ }^{1}$. Tomem-se como objeto as seguintes frases:

/*udake udantu/ "nadem na água!",

/*asti pradeçe äcäryas/ "o mestre está na região",

/*aho anadatā hate/ "ai! ele se mata pelo jejum!" e

I"prabho upagaccha/ "Senhor, aproxima-te!"

Morfologicamente atentas a derivação gramatical e sintaticamente organizadas segundo uma vontade qualquer, elas carecem, no entanto, para seu enunciador, em forma oral, das marcas definitivas de sua enunciação. Segundo 0 texto em questão, sutra 9.II, ekäro 'yam/ "e se torna ay", as primeiras se realizam da seguinte maneira:

/udakay undantu/e

/asti pradeçay äcäryah/; ${ }^{2}$

1. WHIINEY, W. D. The Taittiriya-pratisäkhya. Delhi: Motilal Banarsidass, 1973 [New Haven, 1868].

2. Idem, p. 212. 
segundo o sutra 9.L2, okäro 'vam/ "o se torna av", as segundas são pronunciadas:

\section{/ahav anadatä hate/ e}

/prabhav upagaccha/. ${ }^{3}$

Documenta, entretanto, o texto, em 10.19, uma solução particular: lupyete tv avarnapürvau yavakärau/ "mas y e v são elididos quando precedidos de a" - 0 que leva as frases em questão a assumirem as seguintes formas finais:

/udaka undantu/,

/asti pradeça äcäryah/,

/aha anadatä hate/ $\mathrm{e}$

/prabha upagaccha/. ${ }^{4}$

Claro fique que estas são as formas que esses encontros fonéticos assumem - podem assumir - na forma do Sânscrito desse registro verificável entre os taittiriyanos. Como bem esclarece o mesmo texto, outros falantes, que adotam outras normas, não as pronunciaram do mesmo modo. Com efeito, o sutra 10.20, nokhyasya/ "Não, segundo Ukhya", anota:

/udakay undantu/,

/asti pradeçay äcäryaḥ/,

/ahav anadatá hate/ $\mathrm{e}$

/prabhav upagaccha/. ${ }^{5}$

Diferentemente, "Não o V, segundo Säminntyah", conforme o sutra 10.21, vakäras tu sämkrtyasya - 0 que levaria às seguintes formas:

/udaka undantu/,

/asti pradeça àcāryah/,

/ahav anadatä hate/ $\dot{e}$

/prabhav upagaccha/. 6

Por outro lado, conforme o sutra 10.22, ukäraukäraparau lupyete mäcākìyasya/ "Segundo Mácākìya, ambos são elididos se seguidos de u ou o". Neste caso, as frases seriam pronunciadas do seguinte modo:

/udaka undantu/,

/asti pradeçay äcäryah/,

/ahav anadatá hate/ $e$

/prabha upagaccha/. ${ }^{7}$

Para finalizar, Segundo Vātsapra, $\left[\begin{array}{lllll}0 & y & \text { e } & 0 & \mathbf{v}\end{array}\right]$ são pronunciados imperceptivelmente, como afirma o sutra 10.23 , leço vätsapra-syaitayoh $/{ }^{8}-\mathrm{em}$ qualquer caso, dirá Pānini em 8.3.18, apontando para o fato de que na fala culta cotidiana de sua região e de sua época é este o modo de resolução desse encontro fonético e endossando informação anterior de Çäkațāyana ${ }^{9}$.

\footnotetext{
3. Idem, p. 213.

4. Idem, p. 237.

5. Idem, p. 238.

6. Idem, Ibldem.

7. Idem, p. 239.

8 Idem, p. 240.

9. vayor laghuprayatnatarah fảkatāyanasya/ - para Sumitra Katre, tradutor ${ }_{2}$ o v e o y são "more lightly pronounced, requiring lax articulation, a glide sound". Cf. Astädhyajyi of Päníni. Delhi: Motilal
} 
Com relação à semântica, já Yāska, em seu Nirukta, muito mais que uma "Etimologia", discutia com um cético Kautsa, para quem "as palavras dos Vedas, com efeito, não têm referente" (anarthakä hi manträh/) e "além disso, são de referente obscuro" (athäpy avistärthä bhavanti) ${ }^{10}$. Como Yāska esta, na verdade, fazendo um estudo das vărias possibilidades analíticas $e$ analógicas de "notificabilidade / referencialização" (vijnäptimätratä) operadas entre 0 signo e 0 objeto que ele faz significar, e isso a partir de uma lista de palavras naigama de origem "védica" - ele dirá, por exemplo, como nos nossos melhores exemplos de "etimologia popular", que duhitr remete analogicamente a "filha" porque esta ligado a /düre + hitä/ "bom quando colocado a distância" 11 - , dirá Yäska, respondendo a Kautsa, que "elas [as palavras védicas] são referencializantes por causa da semelhança de signo" (arthavantạ̣ çabdasämānyät) - quer dizer: referentes de um já histórico sânscrito vèdico não se perderam na fala cotidiana (laukika) sobre a qual esta discorrendo. Com relação à obscuridade, dirá, no final desse parágrafo 1.16, "não que é culpa do poste se um cego não o vế; a culpa é do próprio homem" (narșa sthänor aparādho yad enam andho na paçyati/ purușāparādhạ sa bhavati/) ${ }^{12}$. Isto é: não é que as palavras dos textos védicos, alguns elaborados por volta do sécilo XV a. C., sejam incompreensíveis e obscuras nesse século VII em que eles viviam: na convivência sincrônica de uma bhäsả que incorporou elementos arcaicos com uma norma naigama (= "védico literário") por si mesma arcaica preservada nas recitações feitas pelos sacerdotes em seus rituais e suas prédicas Kautsa não percebe que o sistema é o mesmo que, se diferenças existem, elas se devem a formalizações semânticas diferenciadas históricamente. 0 que não impede que existam trocas entre elas, que uma influa sobre a outra ou melhor, que raízes arcaicas (védicas) influam no atual, e vice-versa, como atesta o próprio Yāska em 2.2: athapi bhașikebhyo dhätubhyo naigamäh kṛto bhäșyante/ damünäh/ kșetrasādhā iti/ athāpi naigamebhyo bhäșikăḥ/ ușnamam/ ghṛtam iti/ - "Além disso, formas naigama [0 arcaico vivo, o que vem do nigama] são derivados de raízes [da fala de agora], como damüna ['dedicado à casa'], ksetrasädhä ['que divide as terras']. Além disso, [formas] bhäșika [são derivadas de formas] naigama como usna, ['quente'], ghrta ['manteiga clarificada']" ${ }^{13}$. É só com a consideração dessa variação sincrônica, resultante no caso de uma mudança diacrônica, que se consegue superar o paradoxo aparente de uma norma presente influindo numa norma passada. Há razões históricas para iso: nesse século VII, de reestruturação do Vedismo em Bramanismo, aquilo que de estritamente "védico" aindasobrevivia está sofrendo influência / alteração / substituição por um conteúdo "bramânico". Com toda certeza, visões parciais dessas diferenças, no plano da referencialização (e, por conseguinte, da significação), estão na própria base do rstilhaçamento do Vedismo, de que as Upanișad darão mostras. É isso o que justifica o próprio

Banarsidass, 1989, p. 1020. A respeito dessa mesma solução, diz WHITNEY, op. cht., p. 240, que ela esta apontada também nos prätiçäkhya do Atharvaveda (2.24) e da escola Väjasaneyin (4.126) apontando, desse modo, para uma fixação mais ampla da solução.

10. SARUP, Lakshman. The Nighantu and the Nirukta. Delhi: Motilal Banarsidass, 1967 [1926], 1.15, p. 16.

11. Idem, 3.4, p. 39.

12. Idem, p. 17

13 Idem, p 22 
ceticismo de Kautsa, a quem se dirigem as constantes anotações de Yāska com relação a usos doferentes de elementos lingüisticos na bhäșa (a fala atual) e na anvadhyäya (a fala arcaica védica) - por exemplo, no que diz respeito à "partícula" (nipäta) iva (1.4), que, na anvadhyaya podia marcar tanto uma negação quanto uma comparação (a negação, com um certo torneio de voz, também estabelece uma comparação!), mas, na bhäsạā, introduz apenas uma comparação (a negação agora, e nela, se faz com na) ${ }^{14}$.

É muito fácil, ou mais simples - simplista, na verdade -, tomar a afirmação de Kautsa, sem confrontá-la com as respostas que mereceu, sem colocála no devido contexto, e dizer que os indianos começaram a estudar a "língua" porque ela se tornara incompreensível, os textos necessitavem comentários, etc. se se esquece, além disso, de que era no dia-a-dia das conversas em casa ou na rua ou nas lojas ou nos templos que essas questões se colocavem: afinal, o lugar em que se está nesses séculos dos prätiçäkhya, de Yāska e de Pänini e daí para a frente não é mais o vale do Indo, onde foram compostos tão somente os poemas dos livros 2 a 9 do Rgveda, mas sim o vale do Ganges, onde tudo começou de novo. 0 que era diferente, al se tornou mais agudo: os indianos que emigraram do vale do Indo tiveram de se haver al com uma nova população autóctone, na qual se distinguiram os munda, falantes de uma língua que remarcou os prácritos e, com toda certeza, há de tér obrigado as novas formalizações cultas: por que razão uma norma literária qualquer, mesmo a mais estilisticamente elaborada, gerada al no Ganges, difere tanto de qualquer norma védica embora caiba no mesmo sistema? por que razão o Mahäbhärata é tão diferente lingüisticamente do Rāmäyana? por que é possivel detectar tantas construções não-paninianas no Mahäbhärata se Pānini tivesse que ser a única norma a que se tivesse de obedecer? por que Kälidäsa podia construir uma forma como abhitaptapa "ardardente" $(a b h i+\operatorname{tap}+$ TAP + a) não autorizada por nenhuma norma, a não ser a sua, sem que ela seja considerada "errada" por toda a tradição de analistas indianos de sua linguagem? ${ }^{15}$

REsume: L'auteur aligne, avec quelques exemples extraits de la phonologie, la phanétique, la sémantique, la morphologie et la syntaxe sanskrites, quelques arguments pour la corroboration de l'idée selon laquelle toute la téorie linguistique développée dans l'Inde ancienne a été fondée sur la constatation de la variation linguistique éprouvée dans la vie quotidienne et représentée à la longue dans des formes les plus variées de la langue indienne.

14. Idem, pp. 7-8.

15. Para ampliação dessa discussão, ver outros artigos do Autor publicados em BHÁRATA 1(1990), 4(199I) e 5-7(1992). 